九州大学学術情報リポジトリ

Kyushu University Institutional Repository

Rhodamine B Photocatalytic Degradation using Cu0 Particles under UV Light Irradiation for Applications in Industrial and Medical Fields

Nur Izzah Iwanina Zamri

Department of Chemistry, Faculty of Science, Universiti Brunei Darussalam

Siti Lai latul Noramalina Zulmajdi

Department of Chemistry, Faculty of Science, Universiti Brunei Darussalam

Kusrini, Eny

Department of Chemical Engineering, Faculty of Engineering, Universitas Indonesia

Ayuningtyas, Karina

Department of Chemical Engineering, Faculty of Engineering, Universitas Indonesia

他

https://doi.org/10.5109/4055233

出版情報：Evergreen. 7 (2)，pp.280-284，2020-06. 九州大学グリーンテクノロジー研究教育センター バージョン：

権利関係 : 


\title{
Rhodamine B Photocatalytic Degradation using CuO Particles under UV Light Irradiation for Applications in Industrial and Medical Fields
}

\author{
Nur Izzah Iwanina Zamri1 ${ }^{1)}$, Siti Lailatul Noramalina Zulmajdi ${ }^{1)}$, Eny Kusrini ${ }^{2 *}$, \\ Karina Ayuningtyas ${ }^{2}$, Hartini M. Yasin ${ }^{1)}$, Anwar Usman ${ }^{1 *}$ \\ ${ }^{1}$ Department of Chemistry, Faculty of Science, Universiti Brunei Darussalam, Jalan Tungku Link, Gadong \\ BE1410 Negara Brunei Darussalam \\ ${ }^{2}$ Department of Chemical Engineering, Faculty of Engineering, Universitas Indonesia, Kampus Baru UI-Depok, \\ 16424, Indonesia
}

\author{
*Author to whom correspondence should be addressed: \\ E-mail: : ekusrini@che.ui.ac.id (EK); anwar.usman@ubd.edu.bn (AU)
}

(Received November 6, 2019; Revised May 20, 2020; accepted May 21, 2020).

\begin{abstract}
In this paper, the kinetics of photoinduced degradation of rhodamine $\mathrm{B}(\mathrm{RhB})$ in aqueous solution utilizing synthesized copper oxide $(\mathrm{CuO})$ particles as catalyst has been studied by measuring the absorbance of the dyes at various time intervals. The $\mathrm{CuO}$ particles were fabricated using sol-gel method, and calcined at different temperatures in the range from 450 to $750{ }^{\circ} \mathrm{C}$. The crystallinity of the CuO particles was confirmed using powder X-ray diffraction. The highest RhB degradation efficiency was only $10.9 \%$ by the $\mathrm{CuO}^{550}$ upon $\mathrm{UV}$ irradiation in $30 \mathrm{~min}$, proving that $\mathrm{CuO}$ particles, regardless of their calcination temperature, showed poor photodegradation activity.
\end{abstract}

Keywords: activation energy, copper oxide particles, photocatalysis, rhodamine B, sol-gel

\section{Introduction}

Toxic substances, such as synthetic dyes of effluents from textile industries, are often discharged directly to sewage systems, causing contaminations to lakes and rivers. There are a large number commercially available synthetic dyes which were produced in a massive scale. During the dyeing process some amounts of applied synthetic dyes are lost and include in the wastewater as they are well soluble in water ${ }^{1}$. The dyes absorb most of the sunlight in the UV and visible region, thus they make the water system light impenetrable and high resistivity to aerobic digestion. Moreover, the synthetic dyes, even at trace concentrations, can cause severe risks to living organisms in the aquatic life and the water resources. Finally, it can be dangerous to the entire ecosystem. Therefore, it is important to find a more suitable and efficient wastewater treatment technologies ${ }^{2-4)}$.

Conventional methods for eliminating dyes such as using liquid membrane ${ }^{5)}$, ozonation ${ }^{6)}$, and adsorption ${ }^{7-10 \text { ) }}$ are expensive and not very effective ${ }^{11)}$. A promising approach to decompose organic dyes with superior activity is the heterogeneous photocatalysis ${ }^{12,13)}$, which can be a clean, low-cost, and environmentally friendly remediation method ${ }^{14,15)}$. Photocatalysis is already a wellknown method to degrade environmental pollutants, particularly synthetic dyes ${ }^{16)}$, because reduction potentials of organic dyes are much lower than the energy of electron of catalyst in the excited state. For example, highly crystallized tungsten trioxide $\left(\mathrm{WO}_{3}\right)$ loaded $\mathrm{TiO}_{2}$ composite $\left(\mathrm{TiO}_{2} / \mathrm{WO}_{3}\right)$ for efficient photodegradation of methylene blue under visible light irradiation has been reported ${ }^{17)}$. The ratio of $\mathrm{Pt}$ particles on the $\mathrm{TiO}_{2} / \mathrm{Pt}$ catalyst was determined using transmission electron microscopy (TEM) and X-ray diffraction (XRD). It is similar method that reported by Taira and Einaga ${ }^{18)}$.

Copper oxide $(\mathrm{CuO})$ has a relatively narrow band gap $(1.7 \mathrm{eV})^{19)}$ in near infrared, but it can be utilized as a catalyst because it is a p-type semiconductor oxide, cheap, non-toxic, and stable photochemically ${ }^{20}$. $\mathrm{CuO}$ has been utilized for many applications, such as in electrochemical cells, light emitters, gas sensors, photovoltaic cells, and photoconductive and photothermal materials ${ }^{20-23)}$. The physical, optical, and chemical properties of $\mathrm{CuO}$ nanomaterials depend strongly on their particle size, electronic structure, and surface morphology ${ }^{19)}$.

$\mathrm{CuO}$ particles in nanometer scales show exceptional electronic and optical properties suitable for the 
applications. Interestingly, the $\mathrm{CuO}$ is metallic in bulk; however, they behave like semiconductors when they appear in nanosized scales ${ }^{24)}$.

Rhodamine $\mathrm{B}(\mathrm{RhB})$ is one of synthetic dyes widely utilized to dye silk, leathers, nylon, cotton, wood, and paper, and due to its fluorescence, it is also used in biotechnology ${ }^{5)}$. Thus, $\mathrm{RhB}$ is one of representative model of the textile dyes ${ }^{8,9}$. $\mathrm{RhB}$ is an amphoteric dye, but usually considered as basic due to having overall positive charge. It also belongs to the family of Xanthenes dye ${ }^{25)}$.

In this study, $\mathrm{CuO}$ particles was synthesized using solgel method and used as catalyst to degrade RhB dye under UV light excitation. The photocatalytic degradation of RhB was investigated across different experimental parameters, such as the catalyst dosage, the initial concentration of $\mathrm{RhB}$ dye, and medium temperature to observe their effects on the photocatalytic activity of $\mathrm{CuO}$ particles which were prepared at the different temperatures. This study can be further investigated for applications in industrial and medical fields that are environmentally friendly and efficient.

\section{Experimental}

\subsection{Materials}

Copper(II) chloride dehydrate with purity $\geq 99.0 \%$ was purchased from VWR Chemicals, BDH. Sodium hydroxide and acetic acid were obtained from Merck (Germany). Double distilled water was used to prepare all aqueous solutions throughout this study. All chemicals used in this study were of analytical grade and without any purification.

\subsection{Preparation of $\mathrm{CuO}$ particles}

The CuO particles were prepared using sol-gel method following the procedures previously reported by Kshirsagar and coworkers ${ }^{24)}$. Here, $0.2 \mathrm{M} \mathrm{CuCl}_{2} .2 \mathrm{H}_{2} \mathrm{O}$ in water was mixed with $1 \mathrm{~mL}$ of glacial acetic acid and the mixture was heated to $100{ }^{\circ} \mathrm{C}$ with constant stirring. $8 \mathrm{M}$ of $\mathrm{NaOH}$ was then added dropwise to the heated solution until the mixture was neutralized ( $\mathrm{pH}$ reached 7 ). The mixture turned from green to black. The black precipitate was separated by centrifugation and it was washed with water for at least three times. The obtained precipitate was left to dry at room temperature for 24 hours and then calcined for 1 hour. The temperature of the calcination was set at $450,550,650$, and $750^{\circ} \mathrm{C}$, and hereafter the prepared $\mathrm{CuO}$ particles were labelled as $\mathrm{CuO}^{450}, \mathrm{CuO}^{550}, \mathrm{CuO}^{650}$, and $\mathrm{CuO}^{750}$, respectively.

\subsection{Photocatalytic activity}

The photocatalytic activity of $\mathrm{CuO}$ particles to degrade RhB dye in the aqueous solution under light irradiation (365 nm) was evaluated in details. The UV light radiation is expected to excite solely the electron of the $\mathrm{CuO}$ particles as RhB does not absorb in this region. The suspension was continuously stirred throughout the irradiation to ensure equal distribution of particles. The photoirradiation set up was fully covered to avoid interaction with stray light. After a desired irradiation time from 0 to $30 \mathrm{~min}$, the suspension was then centrifuged at $3000 \mathrm{rpm}$ for $15 \mathrm{~min}$, as previously reported ${ }^{13)}$, followed by filtration method. The supernatant was collected, and its absorption was measured using a UV-visible spectrophotometer (Shimadzu UV-1601PC, Japan). The initial concentrations of RhB were varied ranging from 5 to $15 \mathrm{ppm}$ with $5.0 \mathrm{mg} \mathrm{CuO}$ particles catalyst at room temperature $\left(25^{\circ} \mathrm{C}\right)$. The catalyst dosage was in the range between 1.0 and $7.5 \mathrm{mg}$ with a constant $10 \mathrm{ppm} \mathrm{RhB}$ solution at room temperature. The effect of temperature on the degradation was also investigated by evaluating the photodegradation of $\mathrm{RhB}$ at different temperatures ranging from 25 to $50^{\circ} \mathrm{C}$. The photodegradation of $\mathrm{RhB}$ was assessed by analyzing the absorbance, and the timedependent absorbance data were fitted with single exponential functions.

\subsection{XRD Characterization}

The crystallinity of $\mathrm{CuO}$ particle was analyzed using XRD (Shimadzu XRD-7000) with Cu K $\alpha$ reflection mode.

\subsection{Particle Size Analyzer}

The size distribution of the prepared $\mathrm{CuO}$ particles was determined by dynamic light scattering (DLS) using a digital correlator DLS (BI 9000, Brookhaven Instruments Corp) equipped with a diode-pumped laser (532 nm; 10 $\mathrm{mW})$.

\section{Results and Discussion}

\subsection{XRD Characterization of CuO Particles}

Figure 1 shows the XRD pattern of $\mathrm{CuO}$ particles calcined at different temperatures along with that of commercially available $\mathrm{CuO}$ particles for comparison. It can be seen that $\mathrm{CuO}$ particles exist in a single crystalline phase with a monoclinic structure, even though the $\mathrm{CuO}$ particles were synthesized and calcined at different temperatures from 450 to $750{ }^{\circ} \mathrm{C}$. The set of their $2 \Theta$ peaks at 35.4, 38.9, 48.7, 53.3, 58.6, 61.4, 66.2, and 67.9 was indexed as (-111), (111), (-202), (020), (202), (-113), (-311) and (220) of $\mathrm{CuO}^{22)}$. The XRD pattern was similar observed for the commercial $\mathrm{CuO}$ particles. This results suggested that the prepared $\mathrm{CuO}$ particles have the same crystalline phase with the commercial one. Therefore, one can anticipate that all the $\mathrm{CuO}$ particles in this study have almost similar photocatalytic activity.

The crystallite sizes of the $\mathrm{CuO}$ particles (L) were estimated based on XRD spectrum using Scherrer formula 26):

$$
\mathrm{L}=K \lambda / \beta \cos \theta
$$

where $\lambda(0.15418 \mathrm{~nm})$ is the wavelength $\mathrm{X}$-ray beam in 
nanometer, $\beta$ is the peak width of the diffraction peak profile at half maximum height (in radians), $K$ is the Scherrer constant (which is normally taken to be 0.9 ), and $\Theta$ is the Bragg diffraction angle. The crystallite size of $\mathrm{CuO}$ particles was analyzed to be within 23 to $29 \mathrm{~nm}$ for all samples. This value is not necessarily the same as the particle sizes, where the latter were estimated using DLS ranged from 145 to $200 \mathrm{~nm}$.

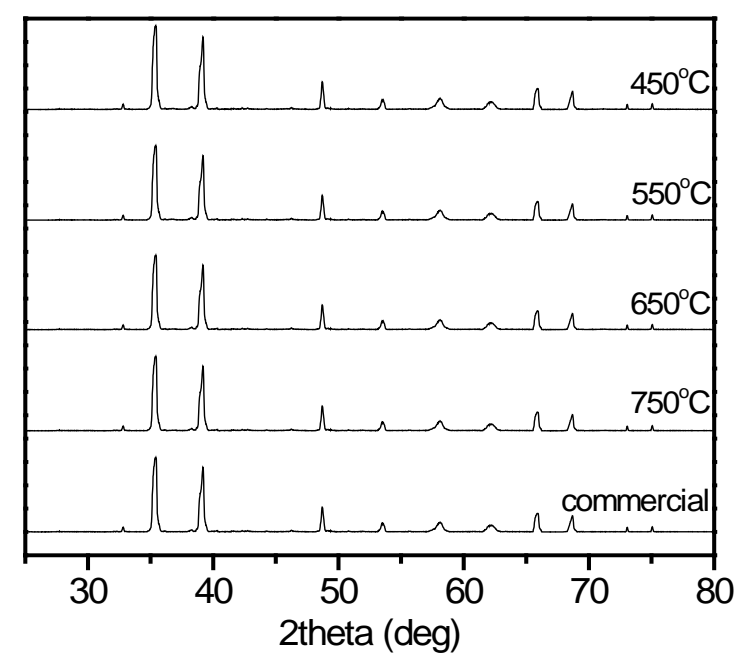

Fig. 1. XRD patterns of $\mathrm{CuO}$ particles calcined at different temperatures for 1 hour.

\subsection{Photocatalytic Degradation of RhB}

The photodegradation rate of $\mathrm{RhB}$ was obtained by fitting the absorbance of the RhB solution as a function of irradiation time. The photodegradation of RhB dye was considered to follow the first order reaction, as represented by Langmuir-Hinshelwood model. This is consistent with the photocatalytic reaction, as usually observed for other organic compounds. The absorption spectra of RhB dye after UV light irradiation up to $30 \mathrm{~min}$ in the presence of $\mathrm{CuO}^{550}$ particles as catalyst (see Fig. 2).

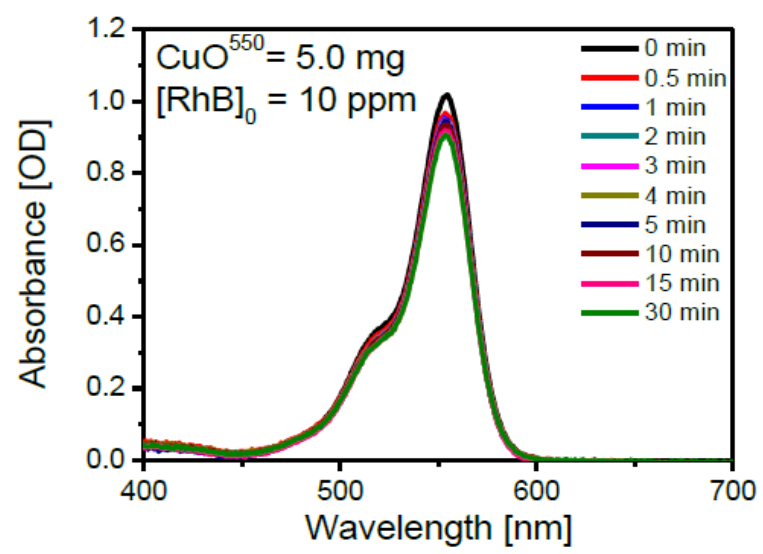

Fig. 2. Time evolution of absorption spectrum of $10 \mathrm{ppm} \mathrm{RhB}$ using $\mathrm{CuO}^{550}$ as catalyst upon UV light irradiation

The photodegradation rate increased with increasing initial RhB concentration up to 7.5 ppm (see Fig. 3). This can be rationalized by considering that there are more $\mathrm{RhB}$ molecules absorbed on the surface of $\mathrm{CuO}$ particles and the RhB undergo photodegradation. At higher RhB dye concentrations, the degradation rate becomes slower. This can be explained on the basis that excessive amount of RhB dye being absorbed and immobilized on the surface of the $\mathrm{CuO}$ particles results in inefficient oxidation of the synthetic dye with the generated free hydroxyl radicals.

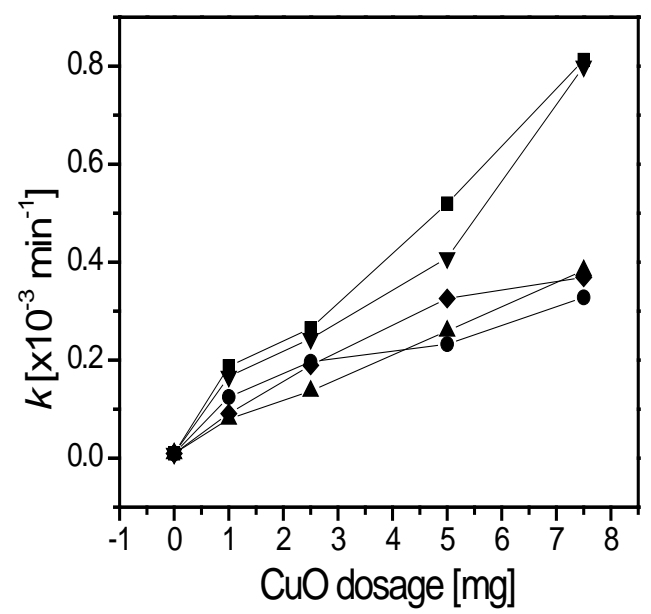

Fig. 3. Plot of $k$ as a function of $[\mathrm{RhB}]_{0}$ at the same amount of catalyst, i.e. $5 \mathrm{mg}$ of $\mathrm{CuO}^{\mathrm{C}}(\boldsymbol{\bullet}), \mathrm{CuO}^{450}(\bullet), \mathrm{CuO}^{550}(\boldsymbol{\Delta})$, $\mathrm{CuO}^{650}(\boldsymbol{\nabla})$ and $\mathrm{CuO}^{750}(\bullet)$ particles. The lines in the graph are only for guidance.

The photodegradation rate of $\mathrm{RhB}$ dye is enhanced with $\mathrm{CuO}$ particles catalyst dosage (see Fig. 4). The degradation rate is faster at higher dosage of $\mathrm{CuO}$ particles because the high dosage of catalyst has a higher probability to absorb the irradiated photons to excite electrons to the conduction band. This leads to the higher concentration of generated hydroxyl radicals responsible to reduce the organic compounds ${ }^{27}$ ). Hence, the results suggested that $\mathrm{CuO}$ particles might have a good photocatalytic performance. The commercial $\mathrm{CuO}$ particles shows a better photo-degradation rate of RhB compared to the $\mathrm{CuO}$ particles synthesized in this study. This highlights the efficient photocatalytic ability as well as inhibition of electron-hole recombination of the $\mathrm{CuO}$ particles. It is also important to mention that, in the presence of higher density of particles, the colloidal mixture become more turbid and absorb the UV light. The larger number of particles in the mixture obviously requires a larger number of irradiated photons, namely higher light power or loner irradiation time. Therefore, under the constant UV light power, large quantities of particles will result in the saturation of photonic efficiency 28). However, this trend was not observed under our experimental conditions, the photodegradation rate of $\mathrm{RhB}$ dye should increase, reach a maximum, and decrease with increasing catalyst dosage of $\mathrm{CuO}$ particles. 


\subsection{Effect of Temperature on RhB Photodegradation}

The effect of medium temperature on photodegradation rate of $\mathrm{RhB}$ dye after 30 min irradiation in the presence of $\mathrm{CuO}$ particles was investigated at temperature from 25 to $50^{\circ} \mathrm{C}$ with a constant catalyst $\mathrm{CuO}$ mass of 5.0 mg using $10 \mathrm{ppm}$ RhB dye in $10 \mathrm{~mL}$. Our findings suggested that the photocatalytic degradation rate of RhB dye increases with increasing temperature (see Fig. 5).

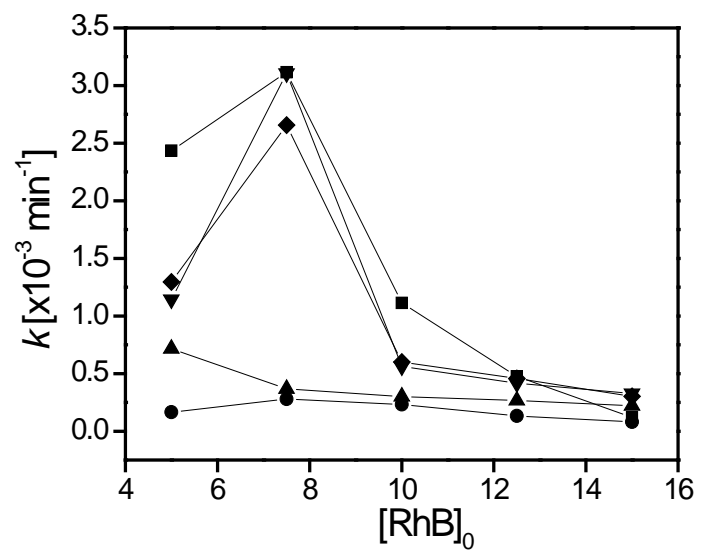

Fig. 4. Plot of $\mathrm{k}$ as a function $\mathrm{CuO}^{\mathrm{C}}(\boldsymbol{\bullet}), \mathrm{CuO}^{450}(\bullet), \mathrm{CuO}^{550}$ $(\boldsymbol{\Delta}), \mathrm{CuO}^{650}(\boldsymbol{\nabla})$ and $\mathrm{CuO}^{750}(\diamond)$ dosage at $[\mathrm{RhB}]_{0} 10 \mathrm{ppm}$. The lines in the graph are only for guidance.

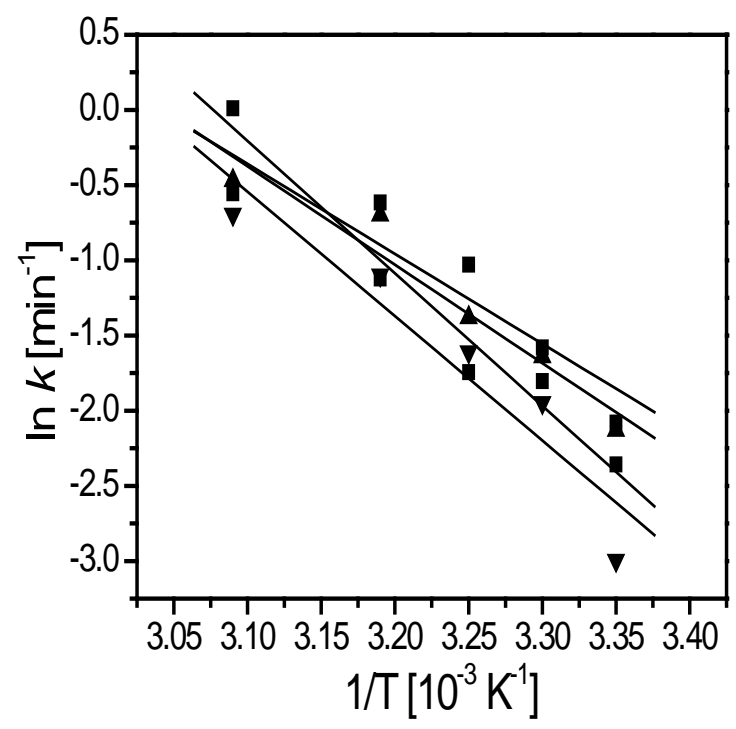

Fig. 5. Arrhenius plot of $k$ against inverse temperature (1/T) of the photocatalytic degradation of RhB dye. The temperature range was 25 to $50^{\circ} \mathrm{C}$, $[\mathrm{RhB}]_{0}$ was $10 \mathrm{ppm}$, and $\mathrm{CuO}^{\mathrm{C}}(\mathbf{\bullet})$, $\mathrm{CuO}^{450}(\boldsymbol{\Delta}), \mathrm{CuO}^{650}(\boldsymbol{\nabla})$ and $\mathrm{CuO}^{750}(\diamond)$ dosage was $5 \mathrm{mg}$. The solid line is the best fit, from which $E_{a}$ was deduced.

The experimental data measured at different temperatures were fitted with Arrhenius equation, $k=$ $A e^{-E_{a} / R T}$, where $A$ is the pre-exponential factor attributed to the frequency of successful oxidation reaction of $\mathrm{RhB}$ dye, $E_{a}$ is the activation energy, $R$ is the universal gas constant (8.314 $\mathrm{J} \mathrm{K}^{-1} \mathrm{~mol}^{-1}$ ), and $T$ is the absolute temperature. Figure 5 shows the Arrhenius plot; $k$ against inverse temperature $(1 / \mathrm{T})$ of the degradation of RhB dye on the $\mathrm{CuO}$ particles under the UV light irradiation. The solid lines shown in Figure 5 are the best fit, from which $E_{a}$ of the oxidation reaction of $\mathrm{RhB}$ on the different $\mathrm{CuO}$ particles was deduced, and the results are summarized in Table 1. It is noteworthy to recall that the photonic activation, namely the generation of electron in the excited sate upon photoexcitation, is the core process of photocatalytic oxidation and reduction. Thus, one can neglect the effect of heating. The $E_{a}$ should be associated to the potential barrier of the photocatalytic degradation which is a diffusion-controlled reaction ${ }^{27}$. In this sense, one could consider that the activated state should be a well solvated structure formed between the RhB dyes and generated hydroxyl radicals. Thus, the $E_{a}$ of the photocatalytic degradation should depend on the diffusion of hydroxyl radicals. The photocatalytic degradation of RhB is controlled by the diffusion and its reaction with hydroxyl radicals on the $\mathrm{CuO}$ catalyst surface $^{15,29)}$. It is explained that photodegradation of RhB dye can be optimized when the $\mathrm{CuO}$ particles in the colloidal solution were well covered by $\mathrm{RhB}$ dye and the hydroxyl radicals were effectively generated on the surface of $\mathrm{CuO}$ particles.

Table 1. Deduced activation energy, $E_{a}$ for $\mathrm{CuO}$ particles on removal of RhB dye

\begin{tabular}{cc}
\hline Sample & $\boldsymbol{E}_{\boldsymbol{a}}\left(\mathbf{k J m o l}^{-\mathbf{1}}\right)$ \\
\hline $\mathrm{CuO}^{\mathrm{c}}$ & 73.2 \\
$\mathrm{CuO}^{450}$ & 49.7 \\
$\mathrm{CuO}^{650}$ & 54.4 \\
$\mathrm{CuO}^{750}$ & 68.8 \\
\hline
\end{tabular}

\section{Conclusion}

In summary, the $\mathrm{CuO}$ particles have been synthesized at different calcination temperatures using sol-gel method and used as catalysts for photocatalyic degradation of RhB dye in aqueous solutions under UV light irradiation. This system can be considered as a suitable model for wastewater remediation treatment. The highest RhB degradation percentage achieved was only $10.9 \%$ by the $\mathrm{CuO}^{550}$ after UV irradiation for 30 minutes, proving that $\mathrm{CuO}$ particles showed poor photocatalytic activity. The interaction between dyes and $\mathrm{CuO}$ particles is important in the photoinduced oxidation and reduction. The activation energy of the photodegradation of RhB dye is related to the diffusion-controlled reaction of free hydroxyl radicals. Further research, a higher catalyst dosage and their composite can be developed for applications in industrial and medical fields that are environmentally friendly and efficient. 


\section{Acknowledgments}

EK would like acknowledge the financial support provided by Universitas Indonesia from PIT9 research grant award No. NKB-0055.UN2.R3.1/HKP.05.00/2019. The authors are also grateful for facilities provided by Universiti Brunei Darussalam.

\section{References}

1) A. R. Khataee and M. B. Kasiri. J. Mol. Catal. A Chem. 328, 8-26 (2010).

2) D. Mohan, K. P. Singh, G. Singh, and K. Kumar. Ind. Eng. Chem. Res. 41, 3688-3695 (2002).

3) R. Slimani, A. Anouzla, Y. Abrouki, Y. Ramli, S. El Antri, R. Mamouni, S. Lazar and M. El Haddad. J. Mater. Environ. Sci. 2, 77-87 (2011).

4) A. M. Tayeb and D. S. Hussein. Am. J. Nanomater. 3, 57-63 (2015)

5) S. K. Tang, T. T. Teng, A. F. M. Alkarkhi, and Z. Li. APCBEE Procedia 1, 110-115 (2012).

6) S. Lalnunhlimi and K. Veenagayathri. Brazilian J. Microbiol. 47, 39-46 (2016).

7) D. Pathania, S. Sharma and P. Singh. Arab. J. Chem. 10, S1445-S1451 (2017).

8) E. Kusrini, B. Wicaksono, Y. Yulizar, E.A. Prasetyanto, and C. Gunawan. IOP Conf. Series: Materials Science and Engineering 316, 012029 (2018).

9) E. Kusrini, O. Sakadewa, G. Pasca, A. Usman, and Y. Yulizar, IOP Conf. Series: Materials Science and Engineering 440, 012029 (2018).

10) M. Mamat, M. A. A. Abdullah, M. A. Kadir, A.M. Jaafar, and E. Kusrini. International Journal of Technology 6, 1103-1111 (2018)

11) P. M. Sabale, P. Kaur, Y. Patel, J. Patel and R. Patel. J. Chem. Pharm. Res. 4, 4921-4936 (2012).

12) K. Wetchakun, N. Wetchakun and S. Sakulsermsuk. J. Ind. Eng. Chem. 71, 19-49 (2019).

13) S. L. N. Zulmajdi, S. N. F. H. Ajak, J. Hobley, N. Duraman, M. H. Harunsani, H. M. Yasin, M. Nur and A. Usman. Am. J. Nanomater. 5, 1-6 (2017).

14) D. I. Anwar and D. Mulyadi. Procedia Chem. 17, 4954 (2015).

15) S. L. N. Zulmajdi, N. I. I. Zamri, A. H. Mahadi, M. Y. H. Rosli, F. Ja’afar, H. M. Yasin, E. Kusrini, J. Hobley and A. Usman. Am. J. Nanomater. 7, 39-45 (2019).

16) J. Jeni, and S. Kanmani. J. Environ. Heal. Sci. Eng., 8, 15-24 (2011).

17) M. Ezaki, K. Kusakabe, EVERGREEN Joint Journal of Novel Carbon Resource Sciences \& Green Asia Strategy, 01 (02), 18-24 (2014).

18) K. Taira, H. Einaga, EVERGREEN Joint Journal of Novel Carbon Resource Sciences \& Green Asia Strategy, 05 (04), 13-17 (2018).
19) A. Tadjarodi, O. Akhavan and K. Bijanzad. Trans. Nonferrous Met. Soc. China English Ed. 25, 36343642 (2015).

20) N. M. Mahmoodi, S. Keshavarzi, and P. Rezaei. (2017). Available: https://www.crossref.org/web Deposit/ [Accessed: 20 October 2018]

21) N. Bouazizi, R. Bargougui, A. Oueslati, and R. Benslama. Adv. Mater. Lett. 6, 158-164 (2015).

22) A. S. Lanje, S. J. Sharma, R. B. Pode, and R. S. Ningthoujam. Library (Lond) v1, 36-40 (2010).

23) S. M. Sathiya, G. S. Okram and M. A. Jothi Rajan. Adv. Mater. Proc. 2, 371-377 (2017).

24) J. Kshirsagar, R. Shrivastava, and P. Adwani. Therm. Sci. 21, 233-242 (2017).

25) T. Aarthi and G. Madras. Ind. Eng. Chem. Res., 46, 7-14 (2007).

26) A. Monshi, M. R. Foroughi, and M. R. Monshi. World J. Nano Sci. Eng., 02, 154-160 (2012).

27) T. C. An, X. H. Zhu and Y. Xiong. Chemosphere 46, 897-903 (2002).

28) R. J. Wu, C. C. Chen, M. H. Chen and C. S. Lu. J. Hazard. Mater. 162, 945-953 (2009).

29) S.L. N. Zulmajdi, N. I. I. Zamri, H. M. Yasin, E. Kusrini, J. Hobley, and A. Usman. React. Kinet. Mechanism Catal. 162, 945-953 (2020). 